D) Check for updates

Cite this: Food Funct., 2020, 11, 8811

\section{(-)-Epicatechin and the colonic metabolite 2,3- dihydroxybenzoic acid protect against high glucose and lipopolysaccharide-induced inflammation in renal proximal tubular cells through NOX-4/p38 signalling $\dagger$}

\author{
David Álvarez Cilleros, ${ }^{a}$ María Elvira López-Oliva, (DD ${ }^{\mathrm{b}}$ María Ángeles Martín ${ }^{\mathrm{a}, \mathrm{c}}$ and \\ Sonia Ramos (D)*a
}

\begin{abstract}
Chronic hyperglycaemia and inflammation are present in diabetes and both processes have been related to the pathogenesis of diabetic kidney disease. Epicatechin (EC) and main colonic phenolic acids derived from flavonoid intake, such as 2,3-dihydroxybenzoic acid (DHBA), 3,4-dihydroxyphenylacetic acid (DHPAA) and 3-hydroxyphenylpropionic acid (HPPA), have been suggested to exert beneficial effects in diabetes. This study was aimed at investigating whether the mentioned compounds could prevent inflammation in renal proximal tubular NRK-52E cells induced by high glucose and lipopolysaccharide (LPS). Pre-treatment of cells with EC and DHBA $(5 \mu \mathrm{M})$ reverted the enhanced levels of pro-inflammatory cytokines, such as tumour necrosis factor- $\alpha$ (TNF- $\alpha$ ), interleukin-6 (IL-6) and monocyte chemoattractant protein 1 (MCP-1), activated by high glucose and LPS. Additionally, EC and DHBA pre-incubation reduced the increased values of adhesion molecules, namely, intercellular cell adhesion molecule-1 (ICAM-1) and vascular cell adhesion molecule-1 (VCAM-1), as well as those of mitogen-activated protein kinases (MAPKs) [extracellular signal-regulated kinase (ERK), -c-jun $\mathrm{N}$-terminal kinase (JNK) and -p38 protein kinase (p38)] activated by the high glucose and LPS challenge. Thus, in EC and DHBA pre-treated cells ICAM-1, p-ERK and p-JNK were returned to control values, and VCAM-1 and p-p38 levels were reduced by $\sim 20$ and $25 \%$, respectively, when compared to high glucose plus LPS-stimulated cells. Likewise, pretreatment with EC and DHBA protected against high glucose plus LPS-triggered oxidative stress by preventing increased ROS and NADPH oxidase 4 (NOX-4) levels ( 25 and 45\% reduction, respectively). By using specific inhibitors of p38 and NOX-4, the participation of both proteins in EC- and DHBA-mediated protection against inflammation and associated oxidative stress was shown. Taken together, EC and DHBA exert beneficial effects in renal proximal tubular cells, as they contribute to preventing the inflammatory-induced milieu and the accompanying redox imbalance, playing NOX-4/p38 a crucial role.
\end{abstract}

Received 10th July 2020, Accepted 24th August 2020 DOI: $10.1039 /$ dOfo01805h rsc.li/food-function

\section{Introduction}

Diabetic kidney disease (DKD) is a major complication of diabetes that affects one-third of diabetic patients and constitutes

\footnotetext{
${ }^{a}$ Department of Metabolism and Nutrition, Institute of Food Science and Technology and Nutrition (ICTAN), Consejo Superior de Investigaciones Cientificas (CSIC), José Antonio Novais 10, Ciudad Universitaria, 28040 Madrid, Spain. E-mail: s.ramos@ictan.csic.es; Fax: +34.91.549.36.27; Tel: +34.91.544.56.07

${ }^{b}$ Sección Departamental de Fisiología, Facultad de Farmacia, Universidad Complutense de Madrid (UCM), Spain

${ }^{c}$ Centro de Investigación Biomédica en Red de Diabetes y Enfermedades Metabólicas Asociadas (CIBERDEM), ISCIII, Spain

$\dagger$ Electronic supplementary information (ESI) available. See DOI: 10.1039/ dofo01805h
}

one of the main causes of death in this disease. ${ }^{1}$ During diabetes, renal tubules are vulnerable to various stimuli, such as high glucose microenvironment and inflammation, among others. Thus, in $\mathrm{DKD}$, chronic hyperglycaemia is associated with early renal tubular damage and contributes to the progression of renal dysfunction. ${ }^{2}$ Additionally, the low-grade inflammation found in diabetes, both systemic and localized in tissues, has been directly associated with the pathogenesis of diabetic complications, including DKD. ${ }^{3}$ Therefore, the enhanced levels of glucose as well as lipopolysaccharide (LPS) and pro-inflammatory factors have been reported in diabetic patients with nephropathy. ${ }^{3,4}$

At the molecular level, during DKD, multiple signalling pathways are altered and directly contribute to the progression 
of the disease, wherein the role of NADPH oxidase 4 (NOX-4) and the three groups of mitogen-activated protein kinases (MAPKs) is crucial: c-jun N-terminal kinase (JNK), p38 protein kinase (p38) and extracellular signal-regulated kinase (ERK), which are also closely linked to the underlying oxidative stress. ${ }^{5}$ Importantly, this complex dysregulation of the signalling network during DKD also leads to the enhanced levels of different inflammatory mediators, such as tumour necrosis factor- $\alpha$ (TNF- $\alpha)$, intercellular cell adhesion molecule-1 (ICAM-1), vascular cell adhesion molecule-1 (VCAM-1), monocyte chemoattractant protein (MCP-1) and interleukin (IL)-6. ${ }^{5}$ In fact, recently DKD has also started to be considered as an inflammatory disease; ${ }^{3}$ therefore, anti-inflammatory agents might be beneficial for the amelioration of this disease. In this regard, it is becoming clear that it is important to counteract the diabetic pathophysiology through different ways using multi-target agents.

Natural compounds constitute a valuable source of chemopreventive agents with regard to chronic diseases. ${ }^{6-9}$ Thus, natural compounds are considered good candidates against chronic diseases, such as diabetes, and also DKD, for their broad range of biological properties due to their ability to modulate multiple targets and lack of toxicity. ${ }^{7-9}$ Among these natural compounds, flavanols, such as (-)-epicatechin (EC), are abundant in cocoa, grapes, tea, and many other fruits and vegetables, ${ }^{6,7,10}$ and are important candidates with demonstrated health-promoting effects, including antidiabetic properties. $^{7-10}$ It has become clear that the health effects of phenolic compounds depend on their bioavailability. ${ }^{7,11-13}$ Thus, when evaluating the impact of polyphenols on health the contribution of both food polyphenols and metabolites, including low molecular weight phenolic acids derived from the colonic intestinal microbiota, should be taken into account. ${ }^{71-13}$ It has been reported that these microbial metabolites constitute a great proportion of the amount ingested, and circulate in the body prior to their urinary excretion. In this line, mono- and di-hydroxylated phenylpropionic and phenylacetic acids are main colonic phenolic acids derived from intake of flavanol-rich food (grapes, apples, pears, legumes, cocoa, wine cider, and beer), ${ }^{11}$ and after being absorbed they could be detected in serum before their elimination via urine; ${ }^{11,12}$ in addition, part of these metabolites could be metabolized by hepatic phase II enzymes (conjugated derivatives). ${ }^{11,12}$ Thus, the concentrations of these phenolic acids in the micromolar range in human plasma and urine after the intake of cocoa products have been reported, ${ }^{14,15}$ contributing to the health-promoting effects. ${ }^{11,12}$ Indeed, similarly to the monomer EC, colonic phenolic acids seem to exert antidiabetic effects by multiple mechanisms. ${ }^{7}$ EC and some colonic polyphenolic metabolites are able to prevent key features of diabetic complications related to insulin sensitivity and oxidative stress, ${ }^{12,16-18}$ and avert inflammation in insulinsensitive tissues. ${ }^{6,9,12,19}$ Nevertheless, the role of the inflammatory cytokines in injury during DKD is largely unknown, and in line with this, it also remains unclear whether EC and the colonic phenolic metabolites derived from the intake of flava- nols exert a protective effect on renal tubular cells against inflammation during diabetes.

Therefore, the goal of this work is to analyse the effects of EC and the microbial-derived flavonoid metabolites 2,3-dihydroxybenzoic acid (DHBA), 3,4-dihydroxyphenylacetic acid (DHPAA), and 3-hydroxyphenylpropionic acid (HPPA) on main inflammatory mediators and on key modulatory mechanisms related to the inflammatory process in renal proximal tubular NRK-52E cells exposed to a high glucose plus LPS challenge.

\section{Materials and methods}

\subsection{Materials and chemicals}

(-)-EC ( $>95 \%$ of purity), DHBA ( $\geq 99 \%$ of purity), DHPAA ( $>98 \%$ of purity), HPPA ( $>98 \%$ of purity), diphenyleneiodonium (DPI), and SB203580 were purchased from Sigma Chemicals (Madrid, Spain). Lipopolysaccharide (LPS) from the E. coli 0111:B4 strain was obtained from Invivogen (Nucliber, Madrid, Spain). TNF- $\alpha$ and IL-6 kits were acquired from R\&D Systems (Abingdon, UK) and Invitrogen (Thermo Fisher, Madrid, Spain), respectively. Anti-ERK1/2 and anti-phosphoERK1/2 recognizing phosphorylated Thr202/Thy204 of ERK1/2, anti-JNK1/2 and anti-phospho-JNK1/2 recognizing phosphorylated Thr183/Tyr185 of JNK1/2, anti-phospho-Thr180/Tyr182p38, and anti- $\beta$-actin were obtained from Cell Signalling Technology (Izasa, Madrid, Spain). Anti-TNF- $\alpha$ (sc-52746), antiIL-6 (sc-57315), anti-VCAM-1 (sc-13160), anti-ICAM-1 (sc-107), anti-MCP-1 (sc-52701), p38 $\alpha$ (sc-535), and anti-NOX-4 (sc30141) were purchased from Santa Cruz Biotechnology (Quimigen, Madrid, Spain). Materials and chemicals for electrophoresis were from BioRad (BioRad Laboratories S.A., Madrid, Spain). Cell culture dishes, glutamine and cell culture medium were from Falcon (Cajal, Madrid, Spain) and Lonza (Madrid, Spain), respectively.

\subsection{Cell culture and treatments}

Rat NRK-52E cells (kindly provided by Prof. Dr Patricio Aller, Centro de Investigaciones Biológicas, CSIC, Madrid, Spain) were grown in DMEM medium containing $5.5 \mathrm{mM}$ D-glucose and $2 \mathrm{mM}$ glutamine, supplemented with $10 \%$ foetal bovine serum (FBS). The cells were maintained at $37{ }^{\circ} \mathrm{C}$ in a humidified atmosphere of $5 \% \mathrm{CO}_{2}$. Subsequently, the experimental treatment was carried out with various concentrations of LPS in the presence of a high concentration of glucose (30 mM), as previously reported ${ }^{20,21}$ in serum-free media for $24 \mathrm{~h}$.

In the experiments with the natural compounds, the cells were treated with different concentrations of EC, DHBA, DHPAA or HPPA (1-10 $\mu \mathrm{M})$ diluted in a serum-free culture medium with $5.5 \mathrm{mM}$ D-glucose and $2 \mathrm{mM}$ glutamine for $24 \mathrm{~h}$ (Fig. 1S†).

To evaluate the protective effect of EC, DHBA, DHPAA and HPPA against LPS plus high glucose challenge, 1-10 $\mu \mathrm{M}$ of each compound were added to the cells for $2 \mathrm{~h}$. Then, the cells were subjected to a challenge with LPS $\left(1 \mu \mathrm{g} \mathrm{mL}^{-1}\right)$ plus glucose $(30 \mathrm{mM})$ for $22 \mathrm{~h}$ (Fig. 1S $\dagger$ ). In the experiments with 
the inhibitors, the cells were pre-incubated with $20 \mu \mathrm{M}$ SB203580 (p38 inhibitor) or $10 \mu \mathrm{M}$ DPI (NADH oxidase inhibitor) for $1 \mathrm{~h}$ prior to EC or DHBA treatment for $2 \mathrm{~h}$, followed by the LPS plus high glucose ( $\mathrm{HG}+$ LPS) challenge (Fig. 1S†).

\subsection{Cell viability assay}

Cell viability was determined using the crystal violet assay. NRK-52E cells were seeded at low density $\left(10^{4}\right.$ cells per well $)$ in 96-well plates. After the treatment, the cells were incubated with crystal violet $(0.2 \%$ in ethanol $)$ for $20 \mathrm{~min}$. The plates were rinsed with water, allowed to dry, and $1 \%$ sodium dodecyl sulfate was added. The absorbance was measured using a microplate reader at $570 \mathrm{~nm}$.

\subsection{TNF- $\alpha$ and IL-6 analysis}

The cells were cultured in 24 -well plates $\left(2 \times 10^{5}\right.$ cells per well), and after the different treatments culture supernatants were collected and the concentrations of TNF- $\alpha$ and IL- 6 were measured by ELISA, following the protocols supplied by the manufacturer and normalized to cell protein concentration. Protein concentration was measured using the Bradford reagent (Bio-Rad, Madrid, Spain).

\subsection{Reactive oxygen species (ROS) generation analyses}

Intracellular ROS were quantified by the DCFH assay as described elsewhere. ${ }^{16,22}$ Briefly, the cells were cultured in 24-well plates $\left(2 \times 10^{5}\right.$ cells per well $)$ and incubated with the different treatments. Then, $5 \mu \mathrm{M}$ DCFH probe was added to the wells and kept for $30 \mathrm{~min}$ at $37^{\circ} \mathrm{C}$. After being oxidized by intracellular oxidants, DCFH becomes dichlorofluorescein (DCF) and emits fluorescence. Fluorescence was measured using a microplate reader (BioTek, Winooski, VT) at $485 \mathrm{~nm} / 530 \mathrm{~nm}$ (excitation/emission wavelengths, respectively).

\subsection{Cell lysate preparation}

The cells were lysed at $4{ }^{\circ} \mathrm{C}$ in a buffer containing $25 \mathrm{mM}$ HEPES ( $\mathrm{pH}$ 7.5), 0.3 M NaCl, $1.5 \mathrm{mM} \mathrm{MgCl}_{2}, 0.2 \mathrm{mM}$ EDTA, $0.5 \mathrm{mM}$ dithiothreitol, $0.1 \%$ Triton X-100, $200 \mathrm{mM}$ $\beta$-glycerolphosphate, $0.1 \mathrm{mM} \mathrm{Na}_{3} \mathrm{VO}_{4}, 2 \mu \mathrm{g} \mathrm{mL}{ }^{-1}$ leupeptin and $1 \mathrm{mM}$ phenylmethylsulfonyl fluoride. The supernatants were collected, assayed for protein concentration using the Bradford reagent (Bio-Rad, Madrid, Spain), aliquoted and stored at $-80{ }^{\circ} \mathrm{C}$ until used for western blotting analysis.

\subsection{Western blotting analysis}

Equal amounts of proteins were separated by SDS-polyacrylamide gel electrophoresis and transferred to polyvinylidene difluoride filters (Merck, Madrid, Spain). Membranes were probed with the corresponding primary antibody (all antibodies were used at dilution 1:1000, except for IL-6, TNF- $\alpha$ and NOX-4 that were employed at $1: 500$ ), followed by incubation with peroxidase-conjugated anti-rabbit (GE Healthcare, Madrid, Spain) or anti-mouse (Sigma, Madrid, Spain) immunoglobulin (1:5000 and $1: 3000$, respectively). Blots were devel- oped using the ECL System (GE Healthcare, Madrid, Spain). Normalization of western blots was ensured by $\beta$-actin and bands were quantified using a scanner and accompanying software.

\subsection{Statistics}

Prior to statistical analysis, data were tested for homogeneity of variances by Levene's test; for multiple comparisons, oneway ANOVA was used, followed by the Bonferroni test when variances were homogeneous or by the Tamhane test when variances were not homogeneous. $P<0.05$ was considered significant. A SPSS version 23.0 program was used.

\section{Results}

3.1. Effects of LPS plus high glucose challenge on cell viability, ROS generation and levels of pro-inflammatory cytokines

Hyperglycaemia and inflammation are present in diabetes, and persistent oxidative stress is a key player in the development and progression of this disease. To establish a model in renal tubules, the cells were exposed to a commonly used high concentration of glucose (30 mM) and increasing doses of LPS for $24 \mathrm{~h}$; then, cell viability, ROS generation and main proinflammatory cytokines were evaluated.

Treatment of NRK-52E cells for $24 \mathrm{~h}$ with all LPS concentrations combined with high glucose (30 mM, HG) did not affect cell viability, indicating that the concentrations selected for the study did not damage cell integrity during the period of incubation (Table 1). Moreover, $30 \mathrm{mM}$ glucose in combination with $1 \mu \mathrm{g} \mathrm{mL} \mathrm{m}^{-1}$ LPS increased IL-6 levels in the culture medium, whereas ROS generation and TNF- $\alpha$ values were already increased with $\mathrm{HG}$ alone and with $\mathrm{HG}$ plus $0.5 \mu \mathrm{g}$ $\mathrm{mL}^{-1}$ LPS, respectively (Table 1). Similarly, as shown in Fig. 1, all tested concentrations of LPS in combination with $30 \mathrm{mM}$ glucose enhanced the expression levels of TNF- $\alpha$ in the cells, and $0.5 \mu \mathrm{g} \mathrm{mL}{ }^{-1}$ LPS + HG already showed an increased IL-6 cellular content. In addition, MCP-1 expression levels were also augmented in $\mathrm{HG}$ plus $1 \mu \mathrm{g} \mathrm{mL}^{-1}$ LPS-stimulated NRK-52E cells (Fig. 1). All these data suggest that a high dose of glucose $(30 \mathrm{mM})$ in combination with LPS $\left(\geq 1 \mu \mathrm{g} \mathrm{mL} \mathrm{m}^{-1}\right)$ is able to induce inflammation and accompanying oxidative stress in NRK-52E cells to simulate a situation that resembles diabetes with a low-grade of inflammation in renal proximal tubular cells.

Since $1 \mu \mathrm{g} \mathrm{mL} \mathrm{m}^{-1}$ LPS + HG was the lowest combination of concentrations that clearly altered the levels of the proinflammatory cytokines tested (TNF- $\alpha$, IL-6 and MCP-1) and the redox status in NRK-52E cells, this was the experimental condition selected for further studies. Indeed, the selected concentrations of LPS and glucose have been widely employed alone or in combination in the inflammatory models of renal cells to resemble a diabetic situation. ${ }^{16,20,21}$ Interestingly, similar circulating levels of glucose and LPS to 
Table 1 Effect of high glucose (HG) and lipopolysaccharide (LPS) treatment on cell viability, ROS generation, and values in the culture media of TNF- $\alpha$ and IL-6. NRK-52E cells were treated with the noted concentrations for $24 \mathrm{~h}$. The results of cell viability and ROS are expressed as a percent relative to the control condition, and cytokine levels were measured by ELISA. Values are mean \pm SD of $6-10$ data. Means in a column without a common letter differ, $P<0.05$

\begin{tabular}{|c|c|c|c|c|c|}
\hline & & Cell viability (\% of control) & ROS (\% of control) & $\mathrm{TNF}-\alpha\left(\mathrm{pg} \mathrm{mL} \mathrm{L}^{-1}\right)$ & $\mathrm{IL}-6\left(\mathrm{pg} \mathrm{mL} \mathrm{L}^{-1}\right)$ \\
\hline Control & & $100.30 \pm 4.68^{\mathrm{a}}$ & $100.13 \pm 5.48^{\mathrm{a}}$ & $15.18 \pm 0.51^{\mathrm{a}}$ & $18.15 \pm 0.48^{\mathrm{a}}$ \\
\hline \multirow[t]{8}{*}{ HG (30 mM) } & \multicolumn{5}{|c|}{$\operatorname{LPS}\left(\mu \mathrm{g} \mathrm{mL}^{-1}\right)$} \\
\hline & 0 & $102.43 \pm 3.75^{\mathrm{a}}$ & $122.13 \pm 8.04^{\mathrm{b}}$ & $15.10 \pm 0.67^{\mathrm{a}}$ & $18.09 \pm 0.76^{\mathrm{a}}$ \\
\hline & 0.25 & $108.94 \pm 9.64^{\mathrm{a}}$ & $122.38 \pm 9.88^{\mathrm{b}}$ & $15.38 \pm 0.65^{\mathrm{a}}$ & $17.87 \pm 1.60^{\mathrm{a}}$ \\
\hline & 0.5 & $107.68 \pm 11.17^{\mathrm{a}}$ & $127.86 \pm 12.52^{\mathrm{b}}$ & $17.21 \pm 0.42^{\mathrm{b}}$ & $18.86 \pm 1.91^{\mathrm{a}}$ \\
\hline & 1 & $109.29 \pm 10.26^{\mathrm{a}}$ & $138.62 \pm 5.07^{\mathrm{c}}$ & $19.97 \pm 0.54^{\mathrm{cd}}$ & $24.50 \pm 1.38^{\mathrm{b}}$ \\
\hline & 1.5 & $106.18 \pm 9.54^{\mathrm{a}}$ & $124.30 \pm 4.53^{\mathrm{b}}$ & $19.19 \pm 0.20^{c}$ & $23.42 \pm 1.05^{\mathrm{b}}$ \\
\hline & 2.5 & $106.21 \pm 11.59^{\mathrm{a}}$ & $126.87 \pm 5.58^{b}$ & $21.04 \pm 0.59^{d}$ & $24.31 \pm 1.62^{\mathrm{b}}$ \\
\hline & 5 & $100.14 \pm 10.21^{\mathrm{a}}$ & $118.87 \pm 6.24^{\mathrm{b}}$ & $20.81 \pm 0.63^{\mathrm{d}}$ & $24.72 \pm 0.73^{\mathrm{b}}$ \\
\hline
\end{tabular}

A)

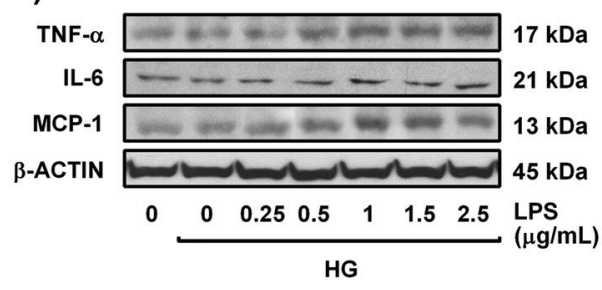

B)

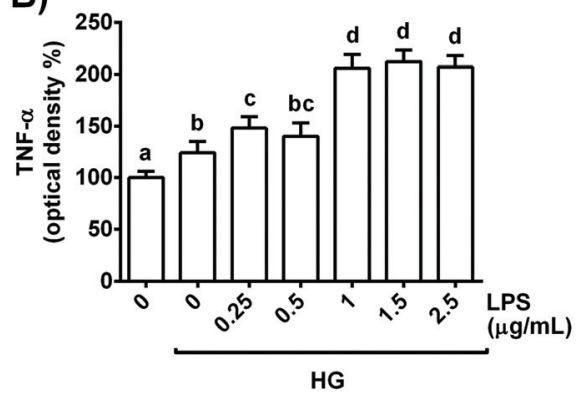

C)

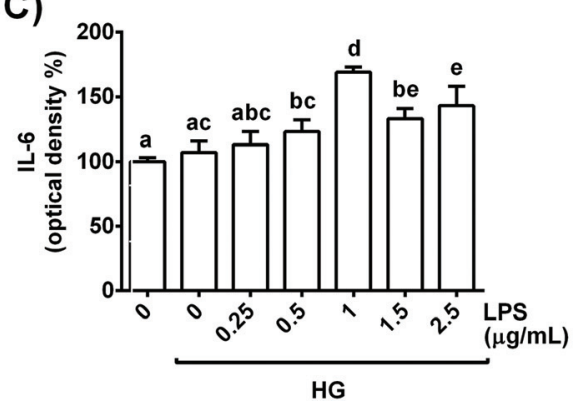

D)

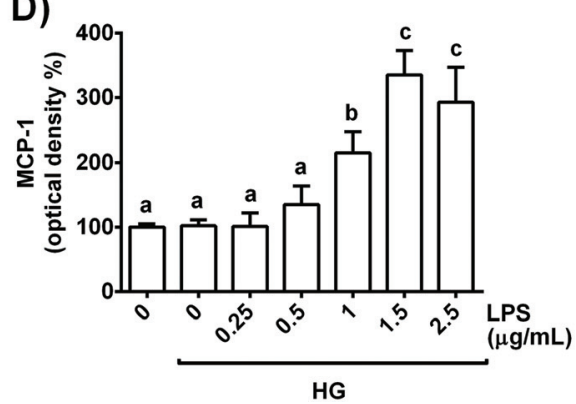

Fig. 1 Dose-dependent effect of LPS in the presence of high glucose $(30 \mathrm{mM})$ on TNF- $\alpha$ and IL-6 levels in NRK-52E cells after $24 \mathrm{~h}$ of treatment. (A) Bands of representative experiments. Percentage data of (B) TNF- $\alpha$, (C) IL- 6 and (D) MCP-1 relative to the control condition (mean \pm SD, $n=$ $5-8)$. Equal loading of western blots was ensured by $\beta$-actin. Means without a common letter differ significantly $(P<0.05)$.

the concentrations selected in this work have been reported in diabetic mice. ${ }^{23}$

\subsection{Direct and protective effects of EC and colonic phenolic metabolites on ROS generation and levels of pro-inflammatory cytokines}

To discard a potential pro-inflammatory effect of EC and microbial phenolic metabolites, NRK-52E cells were treated with doses of EC, DHBA, DHPAA and HPPA (1-10 $\mu \mathrm{M})$ for $24 \mathrm{~h}$ and the levels of TNF- $\alpha$ and IL- 6 were evaluated. The rationale for selecting these concentrations of phenolic compounds is that these doses are considered to be within the range recommended for in vitro studies, and they can be found in biological fluids; ${ }^{11}$ in addition, beneficial effects have been reported with similar concentrations of phenolic compounds in previous studies with cellular models resembling diabetes, including renal cells. ${ }^{6,7,16,17,24}$

As shown in Table 2, none of the tested concentrations of EC or phenolic metabolites increased the levels of TNF- $\alpha$ or IL-6 in the culture medium, indicating no induced cellular inflammation. In agreement with these results, we have already reported that in NRK-52E a 24 h-treatment with the same concentrations of EC and phenolic metabolites used in the present work did not evoke damaging changes or enhanced ROS generation. ${ }^{16,25}$ These results ensure that NRK-52E cells treated with EC or microbial phenolic metabolites $(1-10 \mu \mathrm{M})$ are functional and in competent conditions to face a stressful challenge. 
Table 2 Direct effect of EC, DHBA, DHPAA and HPPA on the values of TNF- $\alpha$ and IL- 6 in culture media. NRK-52E cells were treated with the noted concentrations of the mentioned compounds for $24 \mathrm{~h}$. TNF- $\alpha$ and IL- 6 were analysed by ELISA. Values are mean \pm SD of 6-10 data. Means in a column without a common letter differ, $P<0.05$

\begin{tabular}{llll}
\hline & & TNF- $\alpha\left(\mathrm{pg} \mathrm{mL} \mathrm{m}^{-1}\right)$ & IL-6 $\left(\mathrm{pg} \mathrm{mL} \mathrm{m}^{-1}\right)$ \\
\hline Control & & $15.09 \pm 0.55^{\mathrm{a}}$ & $18.04 \pm 1.63^{\mathrm{a}}$ \\
EC & $1 \mu \mathrm{M}$ & $14.62 \pm 0.48^{\mathrm{a}}$ & $18.76 \pm 1.55^{\mathrm{a}}$ \\
& $5 \mu \mathrm{M}$ & $14.96 \pm 0.62^{\mathrm{a}}$ & $18.33 \pm 1.32^{\mathrm{a}}$ \\
& $10 \mu \mathrm{M}$ & $15.00 \pm 1.04^{\mathrm{a}}$ & $18.08 \pm 1.56^{\mathrm{a}}$ \\
DHBA & $1 \mu \mathrm{M}$ & $15.21 \pm 0.45^{\mathrm{a}}$ & $18.90 \pm 1.41^{\mathrm{a}}$ \\
& $5 \mu \mathrm{M}$ & $15.12 \pm 0.71^{\mathrm{a}}$ & $18.93 \pm 0.94^{\mathrm{a}}$ \\
& $10 \mu \mathrm{M}$ & $14.62 \pm 0.92^{\mathrm{a}}$ & $18.74 \pm 1.16^{\mathrm{a}}$ \\
DHPAA & $1 \mu \mathrm{M}$ & $14.97 \pm 0.57^{\mathrm{a}}$ & \\
& $5 \mu \mathrm{M}$ & $14.86 \pm 0.63^{\mathrm{a}}$ & $19.50 \pm 1.36^{\mathrm{a}}$ \\
& $10 \mu \mathrm{M}$ & $15.20 \pm 0.51^{\mathrm{a}}$ & $18.35 \pm 2.07^{\mathrm{a}}$ \\
HPPA & $1 \mu \mathrm{M}$ & $15.41 \pm 0.75^{\mathrm{a}}$ & \\
& $5 \mu \mathrm{M}$ & $14.94 \pm 0.47^{\mathrm{a}}$ & $19.73 \pm 1.14^{\mathrm{a}}$ \\
& $10 \mu \mathrm{M}$ & $14.91 \pm 0.58^{\mathrm{a}}$ & $18.92 \pm 1.36^{\mathrm{a}}$ \\
& & & \\
\hline
\end{tabular}

Next, to evaluate the potential protective effect of EC and the colonic phenolic metabolites, the cells were pre-treated for $2 \mathrm{~h}$ with EC, DHBA, DHPAA or HPPA $(1-10 \mu \mathrm{M})$ prior to $22 \mathrm{~h}-\mathrm{HG}+$ LPS challenge; then, ROS generation as well as TNF$\alpha$ and IL-6 levels were assayed. Pre-treatment of NRK-52E cells with DHPPA or HPPA did not prevent the enhancement in ROS generation or TNF- $\alpha$ and IL- 6 culture medium values induced by the HG + LPS challenge. Interestingly, 5-10 $\mu \mathrm{M}$ EC and DHBA pre-incubation completely or partly reversed the HG + LPS-induced ROS production and the values of the mentioned pro-inflammatory cytokines, respectively, to the pre-stress levels (Table 3). Therefore, the lowest concentration of both compounds that showed a protective effect against ROS generation and secreted levels of TNF- $\alpha$ and IL- 6 was selected for further studies, that is, $5 \mu \mathrm{M}$ EC and DHBA. In line with this and in agreement with the results obtained from the medium, reduced cellular expression levels of pro-inflammatory cytokines (TNF- $\alpha$, IL-6 and MCP-1) assayed by western blotting were detected in NRK-52E cells pre-incubated with $5 \mu \mathrm{M}$ EC or DHBA in comparison to HG + LPS-stimulated cells (Fig. 2); as mentioned above, the cells incubated with EC or DHBA alone showed similar values of TNF- $\alpha$, IL- 6 and MCP- 1 to those of untreated cells.

\subsection{Effects of EC and DHBA on VCAM-1 and ICAM-1 adhesion protein levels in high glucose plus LPS-exposed renal tubular cells}

Altered levels of adhesion proteins, such as VCAM-1 and ICAM-1, have been associated with different pathologies, such as the sub-chronic inflammation present in diabetes. ${ }^{3}$ To investigate whether the exposure of renal tubular cells to EC or DHBA can prevent the increase in VCAM-1 and ICAM-1 induced by HG + LPS incubation, NRK-52E cells were pretreated with $5 \mu \mathrm{M}$ EC or DHBA for $2 \mathrm{~h}$ and later exposed to the mentioned challenge for $22 \mathrm{~h}$.

Treatment of NRK-52E cells with HG + LPS increased the levels of VCAM-1 and ICAM-1, whereas EC or DHBA alone did not modify the expression of both adhesion proteins when compared to untreated cells (Fig. 3). Likewise, pre-incubation with EC or DHBA prevented the enhancement in ICAM-1 values, showing comparable levels to those of cells treated with EC or DHBA alone (Fig. 3B); however, VCAM-1 values were partially restored to controls by pre-treating the cells with both natural compounds (Fig. 3A).

Table 3 Potential protective effect of EC, DHBA, DHPAA and HPPA on ROS generation and culture medium values of TNF- $\alpha$ and IL-6. NRK-52E cells were treated with the noted concentrations of the mentioned compounds for $2 \mathrm{~h}$, and then HG (30 mM) plus LPS $\left(1 \mu \mathrm{g} \mathrm{mL} \mathrm{m}^{-1}\right) \mathrm{were}$ added for $22 \mathrm{~h}$. The results for ROS are expressed as a percent relative to the control condition, and TNF- $\alpha$ and IL- 6 were measured by ELISA. Values are mean \pm SD of 6-10 data. Means in a column without a common letter differ, $P<0.05$

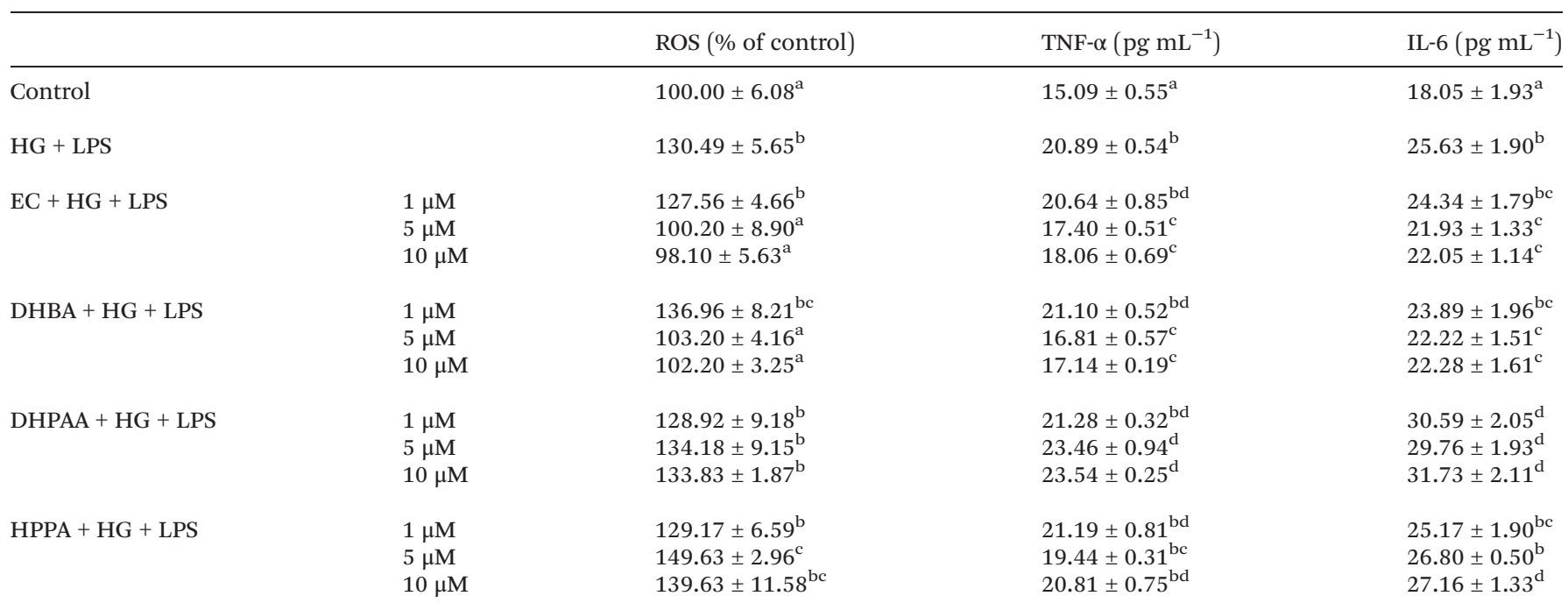


A)

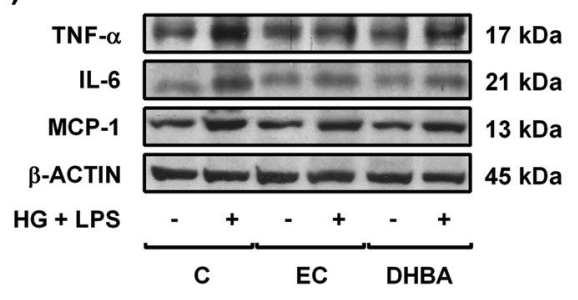

C)

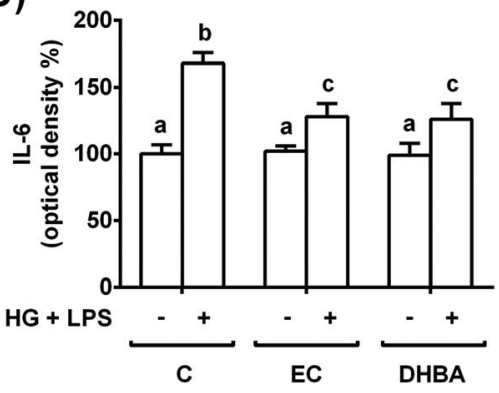

B)

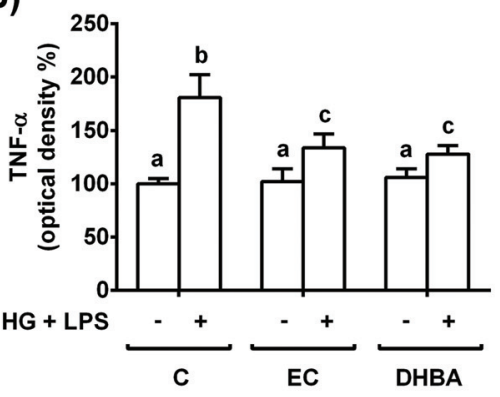

D)

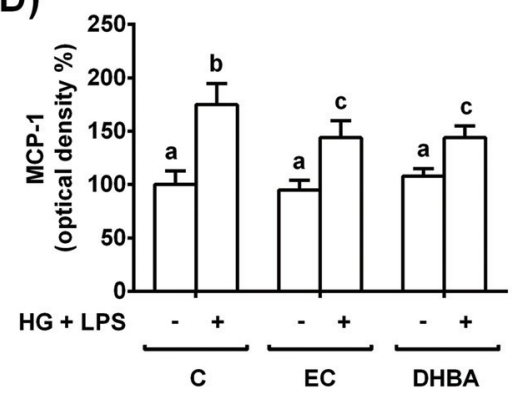

Fig. 2 Protective effect of EC and DHBA on the enhanced levels of TNF- $\alpha$, IL- 6 and MCP-1 induced by the HG + LPS challenge in NRK-52E cells. Cells incubated with $5 \mu \mathrm{M}$ EC or $5 \mu \mathrm{M}$ DHBA for $2 \mathrm{~h}$ were exposed to $30 \mathrm{mM}$ glucose (HG) plus $1 \mu \mathrm{g} \mathrm{mL}^{-1} \mathrm{LPS}$ for additional $22 \mathrm{~h}$. (A) Bands of representative experiments. Densitometric quantification of (B) TNF- $\alpha,(C) I L-6$, and (D) MCP-1. The values are expressed as a percentage relative to the untreated control condition and are mean $+S D, n=7-10$. Equal loading of western blots was ensured by $\beta$-actin. Means without a common letter differ significantly $(P<0.05)$.

A)

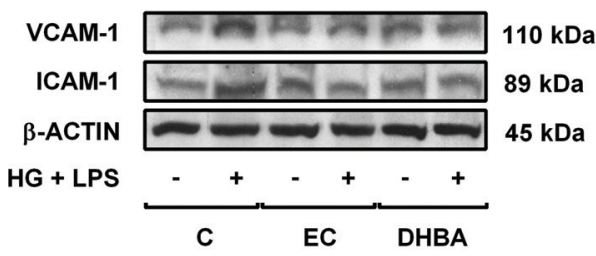

B)

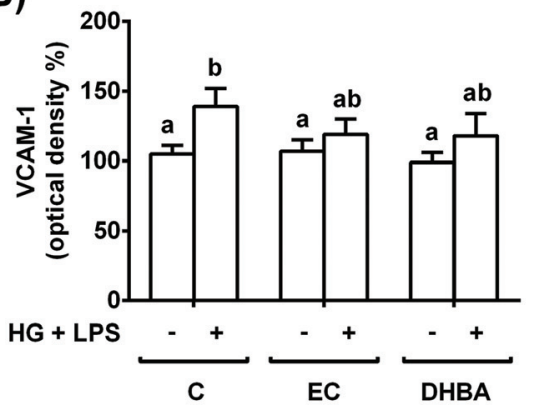

C)

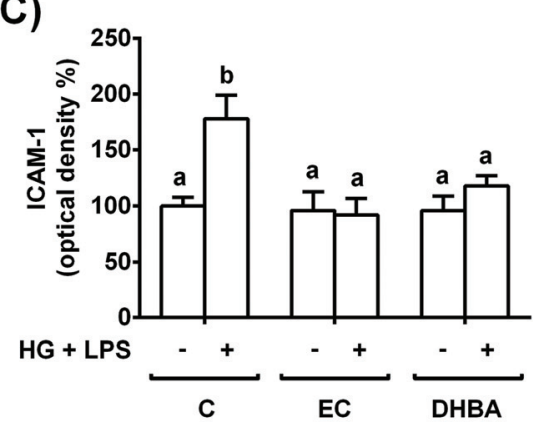

Fig. 3 Protective effect of EC and DHBA on the increased VCAM-1 and ICAM-1 levels induced by the HG + LPS challenge in NRK-52E cells. Cells incubated with $5 \mu \mathrm{M}$ EC or $5 \mu \mathrm{M}$ DHBA for $2 \mathrm{~h}$ were exposed to $30 \mathrm{mM}$ glucose (HG) plus $1 \mu \mathrm{g} \mathrm{mL} \mathrm{m}^{-1} \mathrm{LPS}$ for additional $22 \mathrm{~h}$. (A) Bands of representative experiments. Densitometric quantification of (B) VCAM-1 and (C) ICAM-1 levels. Data are expressed as a percentage relative to the control condition (mean $\pm \mathrm{SD}, n=6-9$ ). Equal loading of western blots was ensured by $\beta$-actin. Means without a common letter differ significantly $(P<0.05)$. 
3.4. Effects of EC and DHBA on MAPK levels in high glucose plus LPS-exposed renal proximal tubular cells

MAPKs are induced by high doses of glucose and inflammatory conditions (LPS) and regulated by oxidative stress. ${ }^{5,24}$ Then, the cells were pre-treated for $2 \mathrm{~h}$ with $5 \mu \mathrm{M}$ EC or $5 \mu \mathrm{M}$ DHBA prior to 22 h-HG + LPS incubation, and phosphorylated, and the total levels of MAPKs were evaluated.

As shown in Fig. 4, the HG + LPS challenge increased the phosphorylated levels of all three MAPKs (p-ERK, p-JNK and p-p38), whereas EC and DHBA alone did not modify any phosphorylated levels of the mentioned proteins in comparison to control cells. In addition, pre-treatment with EC or DHBA returned the enhanced phosphorylated values of ERK and JNK induced by HG + LPS to control values (untreated cells), whereas p-p38 levels were partially repressed when compared to those of untreated cells (Fig. 4). Total levels of ERK, JNK and p38 were not modified by any treatment.

3.5. p38 regulates EC- and DHBA-induced changes in proinflammatory cytokines, ROS and NOX-4 protein levels in high glucose plus LPS-exposed renal tubular cells

Diabetes, inflammation and oxidative stress are linked, wherein MAPKs are a key family of proteins involved in all these processes. ${ }^{5}$ To further determine the potential role of p38-MAPK in the modulation of the pro-inflammatory process induced in HG + LPS-stimulated cells, the effect of a p38 selec- tive inhibitor was assayed. Accordingly, the cells were pre-incubated with $20 \mu \mathrm{M}$ SB (p38 inhibitor) for $1 \mathrm{~h}$ prior to $2 \mathrm{~h}$-treatment with EC or DHBA, followed by HG + LPS incubation (22 h). Fig. $2 \mathrm{~S} \dagger$ shows that in EC and DHBA pre-treated cells, SB reduced p-p38 levels induced by HG + LPS to values that were lower than those of controls. Additionally, as shown in Fig. 5, in cells pre-treated with EC or DHBA, HG + LPS-induced TNF- $\alpha$, IL- 6 and MCP-1 levels were highly blocked when SB was present, showing even lower values than those of control cells. In addition, the production of ROS and levels of NOX-4, which is considered a main source of ROS in the kidneys, ${ }^{26}$ induced by HG + LPS were completely blocked in EC- and DHBA-incubated cells previously treated with the pharmacological inhibitor of p38 (Fig. 6). Altogether, these results suggest that the inhibitory effect exerted by EC and DHBA on p38 phosphorylation could be involved in the repression of cytokine production and induction of oxidative stress (ROS and NOX-4 levels) in NRK-52E cells.

3.6. NOX-4 regulates EC- and DHBA-induced changes in proinflammatory cytokines, ROS and p38 protein levels in high glucose plus LPS-exposed renal proximal tubular cells

As mentioned above, NOX-4 is a main source of ROS in the kidneys, ${ }^{26}$ and oxidative stress is related to the low-grade of inflammation in diabetes. ${ }^{5}$ Then, the effect of NOX-4 inhibition, induced with DPI, on the cells pre-treated with EC or DHBA $(5 \mu \mathrm{M})$ under HG + LPS conditions was analysed in
A)

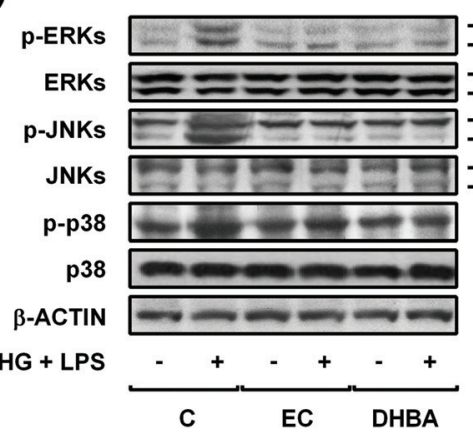

C)

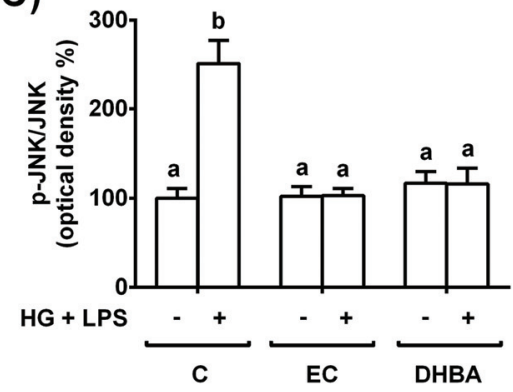

B)
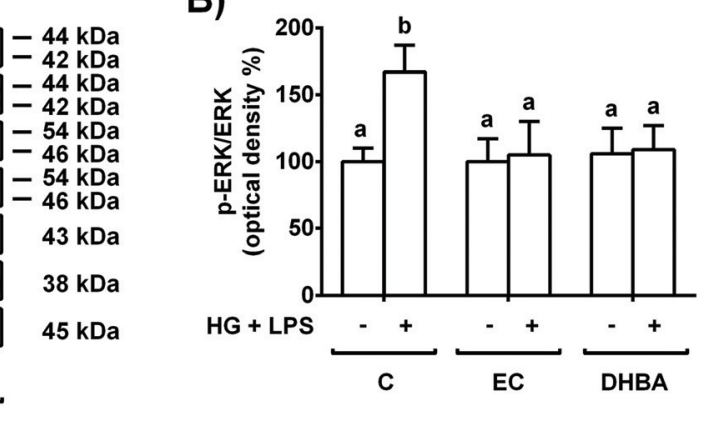

D)

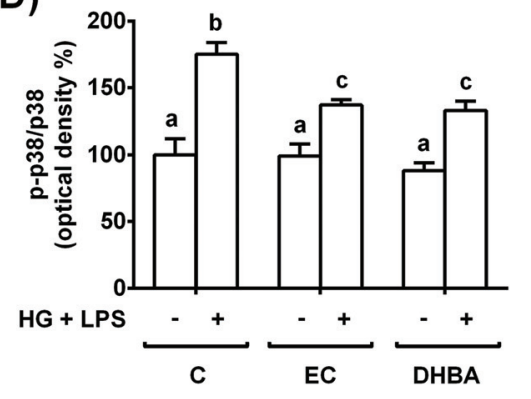

Fig. 4 Effect of EC and DHBA on the levels of phosphorylated and total ERK, JNK and p38 in NRK-52E cells. Cells incubated with $5 \mu \mathrm{M}$ EC or $5 \mu \mathrm{M}$ DHBA for $2 \mathrm{~h}$ were exposed to $30 \mathrm{mM}$ glucose (HG) plus $1 \mu \mathrm{g} \mathrm{mL} \mathrm{L}^{-1} \mathrm{LPS}$ for additional $22 \mathrm{~h}$. (A) Bands of representative experiments. Percentage data of (B) $p-E R K / E R K,(C) p-J N K / J N K$ and (D) p-p38/p38 ratios relative to controls. The values are expressed as a percentage relative to the control condition and are mean $\pm S D, n=6-8$. Equal loading of western blots was ensured by $\beta$-actin. Means without a common letter differ significantly $(P<0.05)$. 
A)

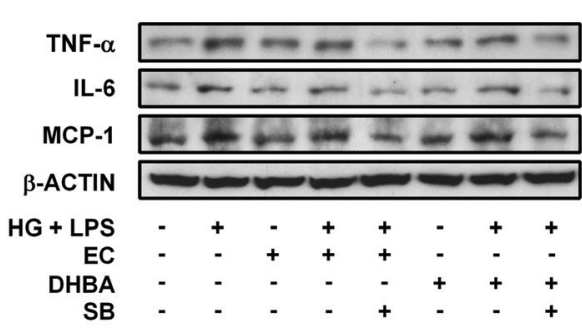

C)

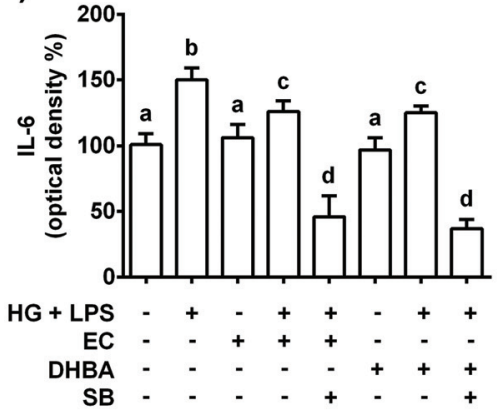

B)

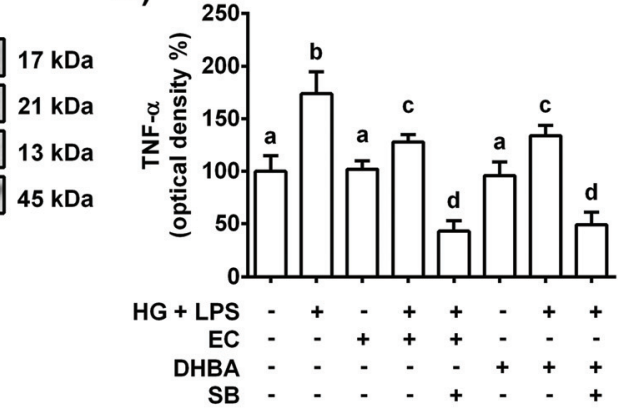

D)

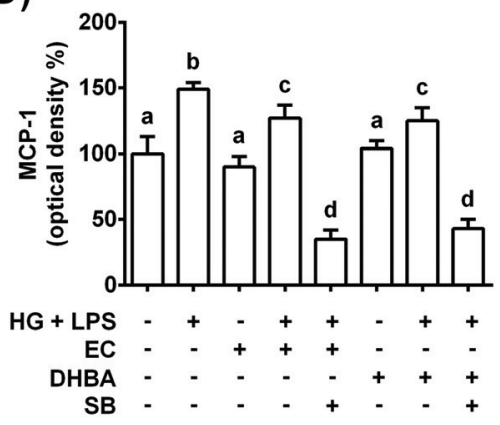

Fig. 5 Effect of EC and DHBA and the selective inhibitor SB (SB203580) on the levels of TNF- $\alpha$, IL- 6 and MCP-1. NRK-52E cells were incubated in the presence or absence of $20 \mu \mathrm{M} \mathrm{SB}$ for $1 \mathrm{~h}$ and later with $5 \mu \mathrm{M} \mathrm{EC}$ or $5 \mu \mathrm{M} \mathrm{DHBA}$ for $2 \mathrm{~h}$, followed by the HG + LPS challenge (22 h). (A) Bands of representative experiments. Percentage data of (B) TNF- $\alpha$, (C) IL-6, and (D) MCP-1 relative to the control condition (mean \pm SD, $n=7-9$ ). Equal loading of western blots was ensured by $\beta$-actin. Means without a common letter differ significantly $(P<0.05)$.

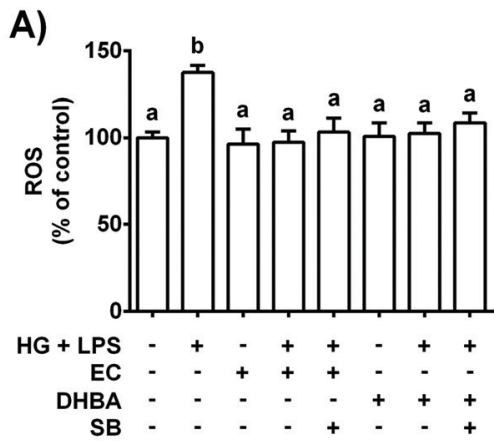

B)

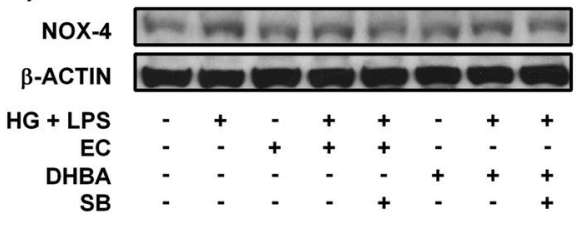

C)

$70 \mathrm{kDa}$
$45 \mathrm{kDa}$

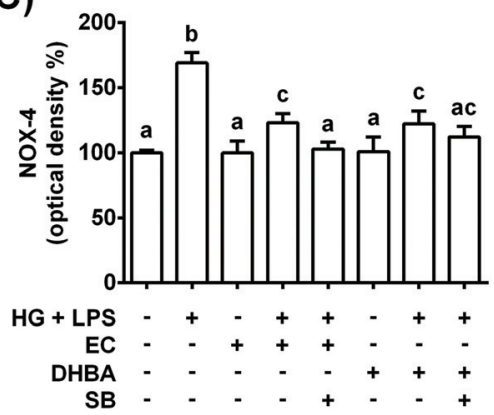

Fig. 6 Effect of EC and DHBA and the selective inhibitor SB (SB203580) on ROS generation and NOX-4. NRK-52E cells were incubated in the presence or absence of $20 \mu \mathrm{M} \mathrm{SB}$ for $1 \mathrm{~h}$ and later with $5 \mu \mathrm{M} \mathrm{EC}$ or $5 \mu \mathrm{M}$ DHBA for $2 \mathrm{~h}$, followed by the HG + LPS challenge (22 h). (A) ROS production is expressed as percent of control are mean \pm SD of 9-12 different samples per condition. (B) Bands of representative experiments. (C) Percentage data of NOX-4 values relative to the control condition (mean \pm SD, $n=6-8$ ). Equal loading of western blots was ensured by $\beta$-actin. Means without a common letter differ significantly $(P<0.05)$. 
A)

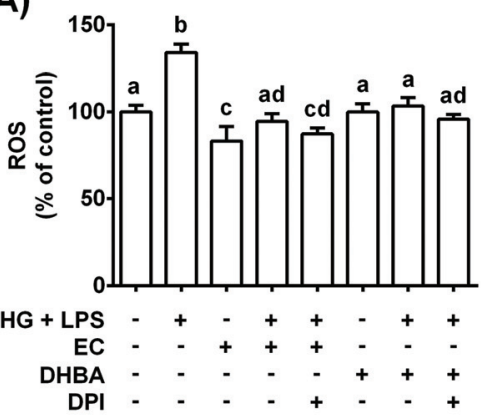

B)

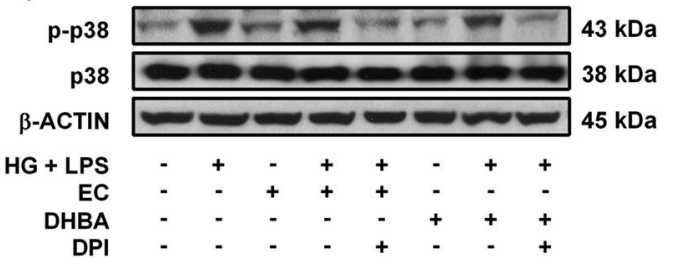

C)

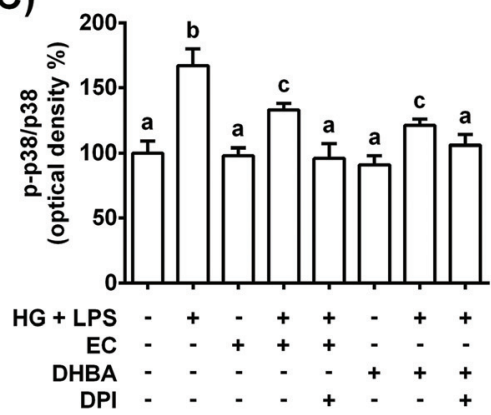

Fig. 7 Effect of EC and DHBA and an inhibitor of NOX (DPI) on ROS generation and levels of $p-38$. NRK-52E cells were incubated in the presence or absence of $10 \mu \mathrm{M} \mathrm{DPI}$ for $1 \mathrm{~h}$ and later with $5 \mu \mathrm{M}$ EC or $5 \mu \mathrm{M}$ DHBA for $2 \mathrm{~h}$, followed by the HG + LPS challenge (22 h). (A) ROS production is expressed as percent of control are mean \pm SD of 7-10 different samples per condition. (B) Bands of representative experiments. (C) Percentage data of $p-p 38 / p 38$ ratios relative to controls (mean \pm SD, $n=7-9$ ). Equal loading of western blots was ensured by $\beta$-actin. Means without a common letter differ significantly $(P<0.05)$.

terms of ROS production, p38, TNF- $\alpha$, IL- 6 and MCP-1 levels. Fig. $3 \mathrm{~S} \uparrow$ shows in EC and DHBA pre-incubated cells with DPI a diminution in NOX-4 levels induced by HG + LPS, showing values lower than those of control cells. Furthermore, as shown above, EC and DHBA pre-treatment totally prevented the increase in ROS generation observed in HG + LPS-stimulated cells, achieving values similar to those of control cells, whereas p-p38 levels showed intermediate values to those of untreated and phenolic-incubated cells (Fig. 7). Similarly, under HG + LPS conditions, the incubation with DPI (blockage of NOX-4) in cells pre-treated with EC or DHBA suppressed the enhancement in ROS production and p-p38 values induced by the HG + LPS challenge, and showed levels comparable to those of EC or untreated cells (Fig. 7). Additionally, in $\mathrm{HG}+$ LPS-stimulated cells previously incubated with DPI and EC or DHBA the increased values of TNF- $\alpha$, IL- 6 and MCP- 1 were completely averted (Fig. 8). All these results suggest that the inhibition of NOX-4 seems to act in a similar manner to that of EC and DHBA to modulate the cellular redox status and to improve the anti-inflammatory protection induced by EC and DHBA.

\section{Discussion}

DKD is a major diabetic complication that contributes to exacerbate the severity and mortality of diabetes. ${ }^{2}$ At present, the inflammatory process has been added to the classical hemodynamic and metabolic alterations as the main cause of renal damage in $\mathrm{DKD}^{3}$ Interestingly, the role of inflammatory cytokines in renal injury during DKD remains still unknown.

Different studies have reported that cocoa and EC possess antioxidant and anti-inflammatory properties. ${ }^{10,16,18,19,22}$ Additionally, it has been shown that cocoa and EC can prevent or delay the injury associated with diabetes by reducing glycaemia and modulating oxidative stress. ${ }^{16,18,19,22}$ After the consumption of flavanol-rich food, mono- and di-hydroxylated phenylpropionic, phenylacetic and hydroxybenzoic acids and conjugated forms are the most abundant metabolites in urine and plasma. ${ }^{11}$ However, it has been proved that conjugation could be a reversible process in vivo, and as a result pure compounds could be accumulated in tissues. ${ }^{27}$ Accordingly, in the present work the potential beneficial effect of EC and most abundant phenolic acids in plasma and urine after the intake of flavanols (DHBA, DHPAA and HPPA) on renal cells in terms of inflammation was investigated. For the first time, it is demonstrated that EC and DHBA attenuate the pro-inflammatory conditions induced by a high dose of glucose combined with LPS through the prevention of the increase in main proinflammatory mediators (TNF- $\alpha$, IL- 6 and MCP- 1 ), adhesion molecules (VCAM-1 and ICAM-1), as well as MAPKs (ERK, JNK and p38) and the diminution of ROS generation. Furthermore, it is shown that EC and DHBA protect NRK-52E cells against 
A)

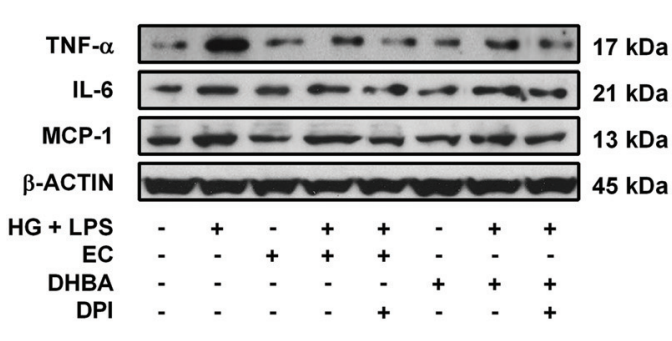

C)

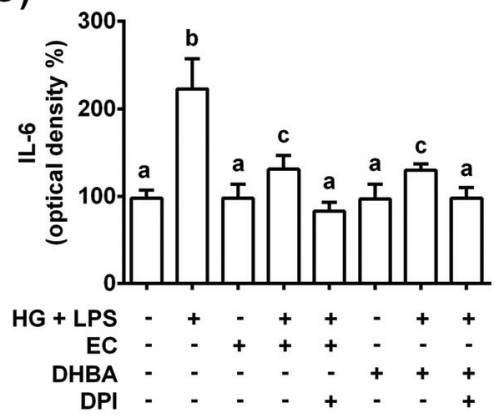

B)

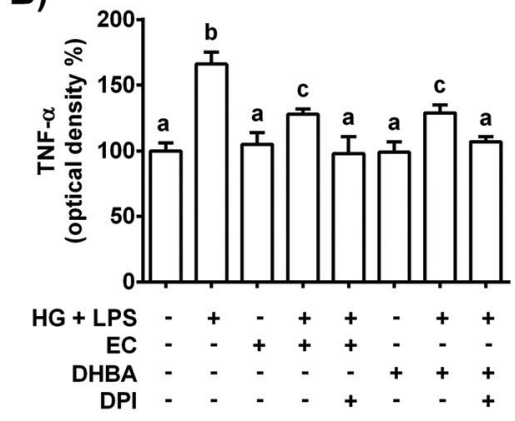

D)

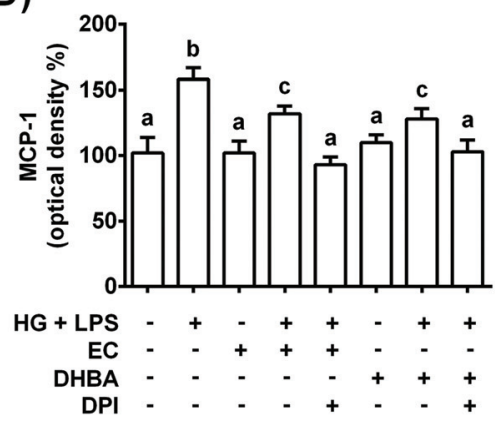

Fig. 8 Effect of EC and DHBA and a NOX inhibitor (DPI) on the levels of TNF- $\alpha$, IL-6 and MCP-1. NRK-52E cells were incubated in the presence or absence of $10 \mu \mathrm{M} \mathrm{DPI}$ for $1 \mathrm{~h}$ and later with $5 \mu \mathrm{M} \mathrm{EC}$ or $5 \mu \mathrm{M}$ DHBA for $2 \mathrm{~h}$, followed by the HG + LPS challenge (22 h). (A) Bands of representative experiments. Percentage data of (B) TNF- $\alpha$, (C) IL-6, and (D) MCP-1 relative to the control condition (mean \pm SD, $n=8-10$ ). Equal loading of western blots was ensured by $\beta$-actin. Means without a common letter differ significantly $(P<0.05)$.

the high glucose plus LPS challenge by modulating key proinflammatory cytokines via p38-MAPK and NOX-4.

During diabetes, the low-grade chronic inflammation has been related to hyperlipidaemia and hemodynamic disarrangements, being the activation of the renin angiotensin aldosterone system, which interacts with nitric oxide and ROS, the prominent feature. ${ }^{4}$ Importantly, the increased glycaemia and endotoxemia also contribute to the pro-inflammatory milieu, this latter resulting mainly from the LPS of Gram negative bacteria ${ }^{28}$ in turn, inflammation has also been associated with the pathogenesis of diabetes complications, including DKD. ${ }^{3}$ Thus, to resemble this situation of low-grade chronic inflammation during diabetes, renal tubular cells were incubated with a high concentration of glucose $(30 \mathrm{mM})$ plus LPS $(1 \mu \mathrm{g}$ $\left.\mathrm{mL}^{-1}\right) \cdot{ }^{20}$ Under these experimental conditions, alterations in the inflammatory response and redox balance without modifying cell viability have also been reported in in vitro and animal models, as well as in diabetic patients. ${ }^{24,29,30}$ In contrast, preincubation of HG plus LPS-stimulated cells with EC or DHBA prevented the enhanced levels of ROS, TNF- $\alpha$ and IL-6. In this regard, it should be considered that the increased levels of pro-inflammatory cytokines have also been related to an augmented oxidative stress and promotion of the renal damage associated with DKD. ${ }^{3,30,31}$ Therefore, prevention of the enhancement in pro-inflammatory cytokines and maintenance of the redox balance by different natural compounds have been connected to an amelioration of kidney damage. ${ }^{16,24,29,31-34}$ Additionally, enhanced IL-6 renal expression has been related to mesangial proliferation and tubular atrophy in several models of renal disease, as well as to the progress of DKD; ${ }^{3,35}$ indeed, decreased IL-6 levels, which might result from treatments with natural phenolic compounds, have been associated with an improvement of kidney functionality in DKD. ${ }^{24,31,32}$

MCP-1 is a chemotactic factor, induced by oxidative stress and high glucose concentrations, ${ }^{35}$ that activates monocytes and macrophages, and promotes their migration to lesions, playing a relevant role in the development of DKD. ${ }^{3,4}$ In the present work, MCP-1 levels were increased in HG + LPStreated cells, but this was highly prevented when the cells were previously incubated with EC or DHBA. Different authors have shown augmented MCP-1 levels in renal diabetic in vivo and in vitro models, as well as in diabetic patients. $^{4,24,36,37}$ However, this enhancement in MCP-1 values, as well as other pro-inflammatory mediators (IL-6 and TNF- $\alpha$ ), was avoided by the administration of different natural phenolic compounds, such as a new chalcone, caffeic acid, ellagic acid, acaí catechin-rich extract, genistein and anthocyanins, promoting a relief of the renal damaging situation. $^{24,29,31,36,37}$

Increased expression levels of TNF- $\alpha$, ICAM-1 and VCAM-1 might be stimulated by hyperglycaemia and/or LPS, and lead to an inflammatory situation in DKD. ${ }^{38}$ ICAM-1 expression can be locally induced by hyperglycaemia, oxidative stress, hyperlipidaemia, hyperinsulinaemia and TNF- $\alpha$, among other factors. ${ }^{4}$ Moreover, different experimental models of 
DKD have shown that ICAM-1 expression is directly associated with the severity of renal damage, and plays a main role in the promotion of macrophage infiltration and DKD. ${ }^{3}$ Thus, reduced levels of ICAM-1 have been connected to an alleviation of inflammation in the diabetic nephropathy and correlated to TNF- $\alpha$ values, ${ }^{4}$ as shown in EC- and DHBA-treated cells. Consistent with this, it has been reported that genistein, a new chalcone and anthocyanins decrease the production of this inflammatory marker in in vitro and in vivo models of DKD. ${ }^{24,36,37}$ In addition, several clinical studies have demonstrated an augmented production of VCAM-1 in renal tubules during DKD. ${ }^{39}$ Accordingly, increased expression levels were observed in HG plus LPS-stimulated cells, but this was highly prevented when the cells were previously treated with EC or DHBA. In line with this, a new chalcone and epigallocatechin3-gallate (EGCG) have shown to ameliorate the expression levels of inflammatory markers, such as VCAM-1 and ICAM-1 in NRK-52E cells and diabetic mice, respectively. ${ }^{24,40}$ Interestingly, these adhesion molecules are also induced by ROS, ${ }^{4,40}$ and in agreement with the present results a parallelism between ROS and adhesion molecule levels (ICAM-1 and VCAM-1) has been reported. ${ }^{40}$ Correspondingly, EGCG improved the redox status by diminishing oxidative stress, leading to the reduced levels of main adhesion molecules (VCAM-1 and ICAM-1) and ameliorated inflammatory renal damage in diabetic mice. ${ }^{40}$

Marked activation of all three MAPKs occurs in DKD, and this feature has been associated with inflammation and the accompanying oxidative stress, ${ }^{5,24}$ as shown. Additionally, pretreatment with EC or DHBA prevented the activation of the three MAPKs in renal tubular cells treated with a high concentration of glucose plus LPS. Similarly, procyanidin B2 decreased the phosphorylation of p38 in renal proximal tubular cells, showing a protective effect. ${ }^{41}$ Consistent with this, other phenolic compounds such as genistein, a novel chalcone and oligonol have demonstrated anti-inflammatory and anti-diabetic effects through the downregulation of MAPKs in vitro and in vivo. ${ }^{24,32,36}$

MAPK-p38 seems to be the MAPK pathway most closely associated with LPS-induced upregulation of inflammatory mediators, and it is also connected to oxidative stress. ${ }^{5,42}$ Therefore, inhibition of p38 would enable to understand better the cross-talk between p38 and the modulation of the cellular inflammatory and redox statuses. In our study, the blockage of p38 reinforced the protective effects exerted by EC and DHBA on high glucose plus LPS-stimulated cells, as diminished values of pro-inflammatory mediators (TNF- $\alpha$, IL-6 and MCP-1), ROS generation and NOX-4 levels were observed. These features suggested that p38 directly or indirectly regulates key proteins to modulate both inflammatory and redox cellular statuses. To the best of our knowledge, the inhibition of p38 induced by flavanols or their metabolites on the previously mentioned parameters in renal tubular cells has not been previously studied. However, it has been demonstrated that the inhibitors of p38 (FR167653 and SB203580) reduce the expression of inflammatory cytokines (IL-1 $\beta$ and TNF- $\alpha$ ) in the kidneys of hypertensive rats, as well as in the hypothalamus and cerebrospinal fluid in a model of inflammation induced by LPS in rats. ${ }^{42,43}$ Additionally, it could be mentioned that these p38 chemical inhibitors improved the redox status of renal cells, ${ }^{43,44}$ showing similar effects to those of the antioxidant $\mathrm{N}$-acetylcysteine (NAC), such as decreased ROS generation and NOX levels. ${ }^{44}$

NOX-4 contributes to the initiation and development of renal injury in $\mathrm{DKD}$, and its inhibition has been associated with an alleviation of the tubular-induced damage. ${ }^{26}$ In agreement, the present results demonstrate for the first time that EC and DHBA prevent HG + LPS-induced NOX-4 expression and contribute to improve both cellular redox and pro-inflammatory statuses. This fact is supported by our findings as inhibition of NOX-4 enhances the protection induced by EC and DHBA in HG + LPS-stimulated cells, showing p-p38 and proinflammatory mediators' levels, as well as ROS generation similar to untreated cells. In agreement, we have demonstrated that the modulation of the redox balance and NOX-4 levels by EC and DHPAA protects NRK-52E cells under high glucose conditions. ${ }^{16}$ Similarly, previous studies performed with an acaí extract, a flavanol-enriched cocoa, NAC and DPI have shown renoprotective effects by reducing ROS generation and NOX-4 expression values. ${ }^{31,45,46}$ Moreover, in renal proximal tubular cells, inhibition of NOX by DPI reduced p-p38 and MCP-1 levels, ROS being involved in these modulatory effects. ${ }^{4,48}$ All these results suggest that EC and DHBA might play a key role in inhibiting NOX-4 and in preventing damage in high glucose plus LPS-stimulated renal tubular cells.

Altogether, it could be highlighted that in the present work it is demonstrated that EC and DHBA possess antiinflammatory activity in renal tubular cells. This effect has already been reported for other phenolic compounds (downregulation of main cytokine levels) also in the kidneys, but the contribution of these inflammatory cytokines to renal injury still remains largely unclear. Moreover, this is the first time that a new regulatory mechanism, in which p38 and NOX-4 play a main role, is proposed for phenolic compounds (EC and DHBA), proving their anti-inflammatory renoprotective effects.

Interestingly, in the present work it is demonstrated that EC and DHBA exert a protective effect against HG + LPS stimuli in NRK-52E cells, whereas DHPAA and HPPA do not show any anti-inflammatory effect. This different outcome could be related to a structure-activity relationship, but this aspect deserves further investigations. In addition, it should be mentioned that after the polyphenol-rich food intake all these phenolic compounds will be present in biological fluids, which might lead to opposite, additive and/or synergistic effects. In this regard, beneficial effects have been reported using simple and complex mixtures of structurally similar flavonoids and/or metabolites in different cellular models; ${ }^{12,17,49}$ indeed, by performing these approaches insights into structure-activity relationships and differential effects on the activities will be provided. 


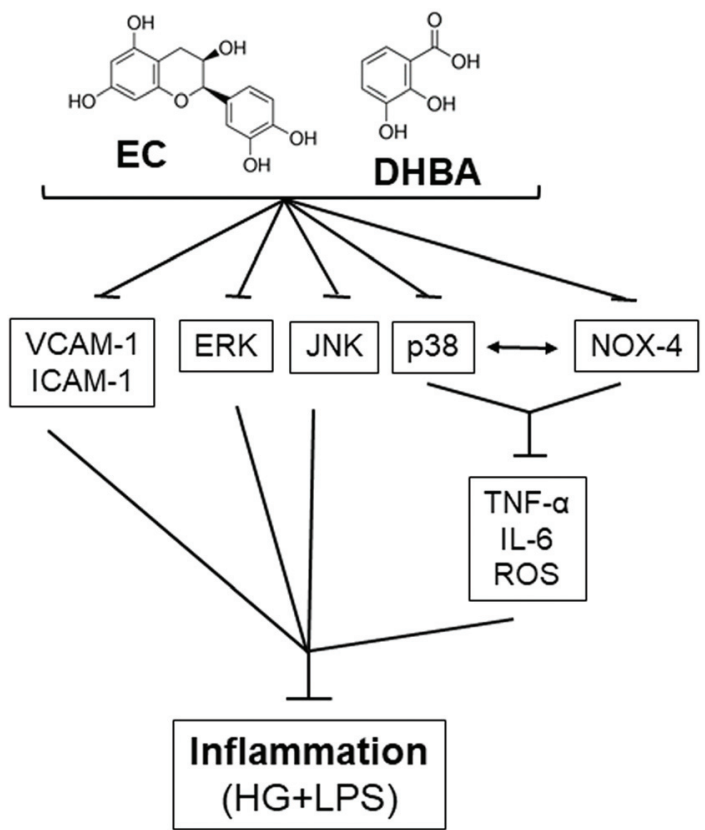

Fig. 9 Schematic overview showing the analysed targets involved in the EC- and DHBA-induced protective effects in NRK-52E cells. The arrows indicate positive inputs (activation), whereas the perpendicular lines show negative inputs (inhibition).

\section{Conclusions}

In summary, EC and the flavanol colonic metabolite DHBA avert inflammation, as under high glucose plus LPS conditions both compounds prevent the enhancement in the inflammatory cytokines (TNF- $\alpha$, IL-6 and MCP-1), adhesion molecules (ICAM-1 and VCAM-1), and MAPK values, and contribute to the balance of the cellular redox status by avoiding the increase in ROS generation and NOX-4 levels (Fig. 9). In addition, a new mechanism has been demonstrated by which EC and DHBA avoid the inflammatory milieu in NRK-52E cells, wherein NOX-4/p38 signalling plays a main role (Fig. 9). Altogether, this study provides new evidence on the renoprotective effects of the flavanol EC and the colonic metabolite DHBA under high glucose plus LPS conditions.

\section{Conflicts of interest}

The authors have declared no conflicts of interest.

\section{Acknowledgements}

This work was supported by the grants AGL2015-67087R and RTI2018-095059-B-I00 (MINECO/FEDER, UE) from the Spanish Ministry of Science and Innovation (MINECO). D. ÁlvarezCilleros is a FPI fellow from the predoctoral program of MINECO (BES-2016-076721). We acknowledge support of the publication fee by the CSIC Open Access Publication Support
Initiative through its Unit of Information Resources for Research (URICI).

\section{References}

1 P. H. Winocour, Diabetes and chronic kidney disease: an increasingly common multi-morbid disease in need of a paradigm shift in care, Diabetic Med., 2018, 35, 300-305.

2 J. M. Forbes and M. E. Cooper, Mechanisms of diabetic complications, Physiol. Rev., 2013, 93, 137-188.

3 J. F. Navarro-González and C. Mora-Fernández, The role of inflammatory cytokines in diabetic nephropathy, J. Am. Soc. Nephrol., 2008, 19, 433-442.

4 A. Fornoni, A. Ijaz, T. Tejada and O. Lenz, Role of inflammation in diabetic nephropathy, Curr. Diabetes Rev., 2008, 4, 10-17.

5 M. K. Arora and U. K. Singh, Molecular mechanisms in the pathogenesis of diabetic nephropathy: an update, Vasc. Pharmacol., 2013, 58, 259-271.

6 L. Goya, M. A. Martín, B. Sarriá, S. Ramos, R. Mateos and L. Bravo, Effect of cocoa and its flavonoids on biomarkers of inflammation: studies of cell culture, animals and humans, Nutrients, 2016, 8, 212, DOI: 10.3390/nu8040212.

7 M. A. Martín, L. Goya and S. Ramos, Antidiabetic actions of cocoa flavanols, Mol. Nutr. Food Res., 2016, 60, 1756-1769.

8 A. Murakami and K. Ohnishi, Target molecules of food phytochemicals: Food science bound for the next dimension, Food Funct., 2012, 3, 462-476.

9 M.-H. Pan, C.-S. Lai and C.-T. Ho, Anti-inflammatory activity of natural dietary flavonoids, Food Funct., 2010, 1, 15-31.

10 Y. Gu, S. Yu and J. D. Lambert, Dietary cocoa ameliorates obesity-related inflammation in high fat-fed mice, Eur. J. Nutr., 2014, 53, 149-158.

11 M. Monagas, M. Urpi-Sarda, F. Sanchez-Patan, R. Llorach, I. Garrido, C. Gomez-Cordoves, C. Andres-Lacueva and B. Bartolome, Insights into the metabolism and microbial biotransformation of dietary flavan-3-ols and the bioactivity of their metabolites, Food Funct., 2010, 1, 233-253.

$12 \mathrm{G}$. Serreli and M. Deiana, In vivo formed metabolites of polyphenols and their biological efficacy, Food Funct., 2019, 10, 6999-7021.

13 V. M. Zamora-Gasga, E. Montalvo-González, G. Loarca-Piña, P. A. Vázquez-Landaverde, J. Tovar and S. G. Sáyago-Ayerdi, Microbial metabolites profile during in vitro human colonic fermentation of breakfast menus consumed by Mexican school children, Food Res. Int., 2017, 97, 7-14.

14 M. Gómez-Juaristi, B. Sarria, S. Martínez-López, L. BravoClemente and R. Mateos, Flavanol bioavailability in two cocoa products with different phenolic content. A comparative study in humans, Nutrients, 2019, 11, 1441, DOI: 10.3390/nu11071441.

15 M. Urpi-Sarda, M. Monagas, N. Khan, R. Llorach, R. M. Lamuela-Raventó, O. Jáuregui, R. Estruch, M. Izquierdo-Pulido and C. Andrés-Lacueva, Targeted 
metabolic profiling of phenolics in urine and plasma after regular consumption of cocoa by liquid chromatographytandem mass spectrometry, J. Chromatogr. A, 2009, 1216, 7258-7267.

16 D. Alvarez-Cilleros, M. A. Martín, L. Goya and S. Ramos, (-)-Epicatechin and the colonic metabolite 3,4-dihydroxyphenylacetic acid protect renal proximal tubular cell against high glucose-induced oxidative stress by modulating NOX-4/SIRT-1 signalling, J. Funct. Foods, 2018, 46, 1928.

17 D. Alvarez-Cilleros, S. Ramos, L. Goya and M. A. Martín, Colonic metabolites from flavanols stimulate nitric oxide production in human endothelial cells and protect against oxidative stress-induced toxicity and endothelial dysfunction, Food Chem. Toxicol., 2018, 115, 88-97.

18 S. D. Quine and P. S. Raghu, Effects of (-)-epicatechin, a flavonoid on lipid peroxidation and antioxidants in streptozotocin-induced diabetic liver, kidney and heart, Pharmacol. Rep., 2005, 57, 610-615.

19 P. D. Prince, C. R. Lanzi, C. G. Fraga and M. Galleano, Dietary (-)-epicatechin affects NF- $\mathrm{\kappa B}$ activation and NADPH oxidases in the kidney cortex of high-fructose-fed rats, Food Funct., 2019, 10, 26-32.

20 W. Huang, H. L. Guo, X. Deng, T. T. Zhu, J. F. Xiong, Y. H. Xu and Y. Xu, Short-chain fatty acids inhibit oxidative stress and inflammation in mesangial cells induced by high glucose and lipopolysaccharide, Exp. Clin. Endocrinol. Diabetes, 2017, 125, 98-105.

21 Y. Shi, Q. Hua, N. Li, M. Zhao and Y. Cui, Protective effects of evodiamine against LPS-induced acute kidney injury through regulation of ROS-NF-kB-mediated inflammation, Evid. Based Complement. Alternat. Med, 2019, 2019, 2190847, DOI: 10.1155/2019/2190847.

22 D. Álvarez-Cilleros, M. E. López-Oliva, M. A. Martín and S. Ramos, Cocoa ameliorates renal injury in Zucker diabetic fatty rats by preventing oxidative stress, apoptosis and inactivation of autophagy, Food Funct., 2019, 10, 79267939.

23 G. Xie, X. Wang, P. Liu, R. Wei, W. Chen, C. Rajani, B. Y. Hernandez, R. Alegado, B. Dong, D. Li and W. Jia, Distinctly altered gut microbiota in the progression of liver disease, Oncotarget, 2016, 7, 19355-19366.

24 Q. Fang, L. Zhao, Y. Wang, Y. Zhang, Z. Li, Y. Pan, K. Kanchana, J. Wang, C. Tong, D. Li and G. Liang, A novel chalcone derivative attenuates the diabetes-induced renal injury via inhibition of high glucose-mediated inflammatory response and macrophage infiltration, Toxicol. Appl. Pharmacol., 2015, 282, 129-138.

25 D. Alvarez-Cilleros, M. A. Martín and S. Ramos, (-)-Epicatechin and the colonic 2,3-dihydroxybenzoic acid metabolite regulate glucose uptake, glucose production, and improve insulin signaling in renal NRK-52E cells, Mol. Nutr. Food Res., 2018, 1700470, DOI: 10.1002/ mnfr.201700470.

26 M. Sedeek, A. C. Montezano, R. L. Hebert, S. P. Gray, E. Di Marco, J. C. Jha, M. E. Cooper, K. Jandeleit-Dahm,
E. L. Schiffrin, J. L. Wilkinson-Berka and R. M. Touyz, Oxidative stress, Nox isoforms and complications of diabetes-potential targets for novel therapies, J. Cardiovasc. Transl. Res., 2012, 5, 590-518.

27 F. Perez-Vizcaino, J. Duarte and C. Santos-Buelga, The flavonoid paradox: conjugation and deconjugation as key steps for the biological activity of flavonoids, J. Sci. Food Agric., 2012, 92, 1822-1825.

28 P. D. Cani, R. Bibiloni, C. Knauf, A. Waget, A. M. Neyrinck, N. M. Delzenne and R. Burcelin, Changes in gut microbiota control metabolic endotoxemia-induced inflammation in high-fat diet-induced obesity and diabetes in mice, Diabetes, 2008, 57, 1470-1481.

29 C. Y. Chao, M. C. Mong, K. C. Chan and M. C. Yin, Anti-glycative and anti-inflammatory effects of caffeic acid and ellagic acid in kidney of diabetic mice, Mol. Nutr. Food Res., 2010, 54, 388-395.

30 S. E. Geerlings, E. C. Brouwer, K. C. Van Kessel, W. Gaastra, R. P. Stolk and A. I. Hoepelman, Cytokine secretion is impaired in women with diabetes mellitus, Eur. J. Clin. Invest., 2000, 30, 995-1001.

31 V. da Silva-Cristino-Cordeiro, G. Freitas-de-Bem, C. A. da Costa, I. Barcellos-Santos, L. Costa-Reis-Marins-deCarvalho, D. Teixeira-Ognibene, A. P. Machado-da-Rocha, J. J. Carvalho, R. Soares-de-Moura and A. Castro-Resende, Euterpe oleracea Mart. seed extract protects against renal injury in diabetic and spontaneously hypertensive rats: role of inflammation and oxidative stress, Eur. J. Nutr., 2018, 57, 817-832.

32 H.-W. Liu, C.-C. Wei and S.-J. Chang, Low-molecular-weight polyphenols protect kidney damage through suppressing $\mathrm{NF}-\mathrm{KB}$ and modulating mitochondrial biogenesis in diabetic db/db mice, Food Funct., 2016, 7, 1941-1949.

33 H. Yousefi-Manesh, S. Hemmati, S. Shirooie, S. M. Nabavi, A. T. Bonakdar, R. Fayaznia, M. H. Asgardoon, A. Z. Dehnavi, M. Ghafouri, J. G. N. Wandjou, G. Caprioli, S. Sut, F. Maggi and S. Dall'Acqua, Protective effects of hydroalcoholic extracts from an ancient apple variety 'Mela Rosa dei Monti Sibillini' against renal ischemia/ reperfusion injury in rats, Food Funct., 2019, 10, 75447552.

34 B. Zhou, Q. Li, J. Wang, P. Chen and S. Jiang, Ellagic acid attenuates streptozocin induced diabetic nephropathy via the regulation of oxidative stress and inflammatory signaling, Food Chem. Toxicol., 2019, 123, 16-27.

35 J. Shi, J. Fan, Q. Su and Z. Yang, Cytokines and abnormal glucose and lipid metabolism, Front. Endocrinol., 2019, 10, 703, DOI: 10.3389/fendo.2019.00703.

36 A. A. Elmarakby, A. S. Ibrahim, J. Faulkner, M. S. Mozaffari, G. I. Liou and R. Abdelsayed, Tyrosine kinase inhibitor, genistein, reduces renal inflammation and injury in streptozotocin-induced diabetic mice, Vasc. Pharmacol., 2011, 55, 149-156.

37 J. Li, S. S. Lim, J.-Y. Lee, J.-K. Kim, S.-W. Kang, J.-L. Kim and Y.-H. Kang, Purple corn anthocyanins dampened highglucose-induced mesangial fibrosis and inflammation: 
possible renoprotective role in diabetic nephropathy, J. Nutr. Biochem., 2012, 23, 320-331.

38 D. Baran, B. Vendeville, M. Ogborn, N. Katz, T. Luu, E. Rubin and V. Nguyen, Cell adhesion molecule expression in murine lupus-like nephritis induced by lipopolysaccharide, Nephron, 2000, 84, 167-176.

39 A. M. Schmidt, J. Crandall, O. Hori, R. Cao and E. Lakatta, Elevated plasma levels of vascular cell adhesion molecule-1 (VCAM-1) in diabetic patients with microalbuminuria: A marker of vascular dysfunction and progressive vascular disease, Br. J. Haematol., 1996, 92, 747-750.

40 W. Sun, X. Liu, H. Zhang, Y. Song, T. Li, X. Liu, Y. Liu, L. Guo, F. Wang, T. Yang, W. Guo, J. Wu, H. Jin and H. Wu, Epigallocatechin gallate upregulates NRF2 to prevent diabetic nephropathy via disabling KEAP1, Free Radicals Biol. Med., 2017, 108, 840-857.

41 D. Li, T. Zhao, J. Meng, Y. Jing, F. Jia and P. He, Procyanidin B2 inhibits high glucose-induced epithelialmesenchymal transition in HK-2 human renal proximal tubular epithelial cells, Mol. Med. Rep., 2015, 8148-8154.

42 Z. H. Zhang, Y. Yu, S. G. Wei and R. B. Felder, Centrally administered lipopolysaccharide elicits sympathetic excitation via $\mathrm{NAD}(\mathrm{P}) \mathrm{H}$ oxidase-dependent mitogen-activated protein kinase signaling, J. Hypertens., 2010, 28, 806-816.

43 A. Tojo, M. L. Onozato, N. Kobayashi, A. Goto, H. Matsuoka and T. Fujita, Antioxidative effect of p38 mitogen-activated protein kinase inhibitor in the kidney of hypertensive rat, J. Hypertens., 2005, 23, 165-174.

44 X. M. Yao, S. D. Ye, C. C. Xiao, J. F. Gu, D. Yang and S. Wang, Metformin alleviates high glucose-mediated oxidative stress in rat glomerular mesangial cells by modu- lation of p38 mitogen-activated protein kinase expression in vitro, Mol. Med. Rep., 2015, 12, 520-526.

45 A. Papadimitriou, E. B. M. I. Peixoto, K. C. Silva, J. M. Lopes de Faria and J. B. Lopes de Faria, Increase in AMPK brought about by cocoa is renoprotective in experimental diabetes mellitus by reducing NOX4/ TGF $\beta$-1 signaling, J. Nutr. Biochem., 2014, 25, 773784.

46 H. Shimizu, S. Saito, Y. Higashiyama, F. Nishijima and T. Niwa, CREB, NF- $\mathrm{BB}$, and NADPH oxidase coordinately upregulate indoxyl sulfate-induced angiotensinogen expression in proximal tubular cells, Am. J. Physiol.: Cell Physiol., 2013, 304, C685-C692.

47 M. Sedeek, G. Callera, A. Montezano, A. Gutsol, F. Heitz, C. Szyndralewiez, P. Page, C. R. J. Kennedy, K. D. Burns, R. M. Touyz and R. L. Hébert, Critical role of Nox4-based NADPH oxidase in glucose-induced oxidative stress in the kidney: implications in type 2 diabetic nephropathy, Am. J. Physiol.: Renal, Fluid Electrolyte Physiol., 2010, 299, F1348-F1358.

48 T. Umekawa, K. Byer, H. Uemura and S. R. Khan, Diphenyleneiodium (DPI) reduces oxalate ion- and calcium oxalate monohydrate and brushite crystal-induced upregulation of MCP-1 in NRK 52E cells, Nephrol., Dial., Transplant., 2005, 20, 870-878.

49 J. L. di Gesso, J. S. Kerr, Q. Zhang, S. Raheem, S. K. Yalamanchili, D. O’Hagan, C. D. Kay and M. A. O'Connell, Flavonoid metabolites reduce tumor necrosis factor-secretion to a greater extent than their precursorcompounds in human THP-1 monocytes, Mol. Nutr. Food Res., 2015, 59, 1143-1154. 